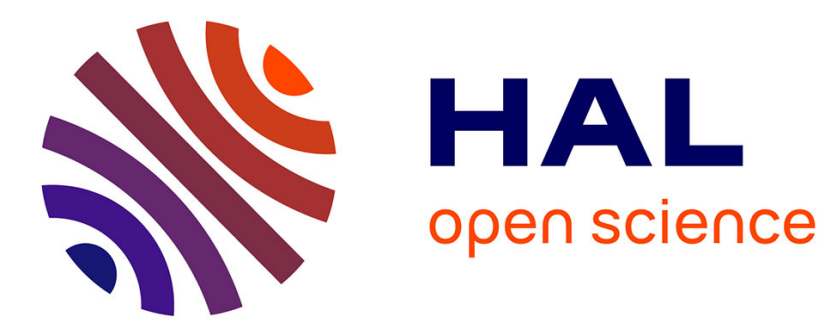

\title{
Study of mass transfer by condensation in humid air for life support systems
}

\author{
A. Tiwari, J.P. Fontaine, J.B Gros, C.G Dussap, Alain Kondjoyan
}

\section{To cite this version:}

A. Tiwari, J.P. Fontaine, J.B Gros, C.G Dussap, Alain Kondjoyan. Study of mass transfer by condensation in humid air for life support systems. 39. Committee on Space Research and Associated Events (COSPAR 2012), Jul 2012, Mysore, India. hal-02744925

\section{HAL Id: hal-02744925 \\ https://hal.inrae.fr/hal-02744925}

Submitted on 3 Jun 2020

HAL is a multi-disciplinary open access archive for the deposit and dissemination of scientific research documents, whether they are published or not. The documents may come from teaching and research institutions in France or abroad, or from public or private research centers.
L'archive ouverte pluridisciplinaire HAL, est destinée au dépôt et à la diffusion de documents scientifiques de niveau recherche, publiés ou non, émanant des établissements d'enseignement et de recherche français ou étrangers, des laboratoires publics ou privés. 


\title{
Study of Mass Transfer by Condensation in Humid Air for Life Support Systems
}

\author{
Akhilesh Tiwari ${ }^{1}$, Jean-Pierre Fontaine ${ }^{2}$, Jean-Bernard Gros $^{3}$, and Claude-Gilles Dussap ${ }^{4}$ \\ Clermont Université, Université Blaise Pascal, Institut Pascal-GePEB axis (UMR 6602), \\ BP10488, F-63000, Clermont Ferrand, France. \\ and \\ Alain Kondjoyan ${ }^{5}$ \\ Institut National de la recherché Agronomie (INRA), UR Qualité des Produits Animaux, \\ F-63122, Saint Genès Champanelle, France
}

The development of life support artificial environments for crews and plants for long duration space flights is a challenge today. The concept of bio-regenerative life support system (BLSS) imitates a simplified natural environment. Experimental or theoretical modeling of BLSS requires a thorough understanding of natural activities from micro to macro scales, like with plant culture for food production, or $\mathrm{CO}_{2} / \mathrm{O}_{2}$ conversion ... Moreover, life support in space relies on both the amount of food and atmospheric $\mathrm{O}_{2}$ produced by plants in a confined space. It is well known that, the enhancement of the gas exchange with leaves and the growth of plants are dependent on the organoleptic and the surrounding thermo-physical factors. Insufficient air movement around plants and/or condensation on plant leaves generally limit their growth by decreasing photosynthetic and transpiration rates. Thus, the optimization of a BLSS will require controlling the airflow and coupled gas/liquid transfer at the plant surfaces. Hence, we have developed an experimental setup at 1-g to study the hydrodynamics and the condensation mass flux on specific geometries in controlled environmental conditions. An air-conditioned closed circuit wind tunnel was used to generate a flow of controlled temperature, hygrometry and hydrodynamics. Condensation of humid air on a small size horizontal flat plate was investigated. The temperature of the active surface is controlled and maintained below the dewpoint to induce condensation. The experiments were performed at ambient temperature, with a relative humidity between $35-70 \%$ and for a velocity range of $1.0-3.0 \mathrm{~m} . \mathrm{s}^{-1}$. The results lead to the evaluation of the local mass transfer coefficients in various conditions. The goal of this study is to develop a theoretical model to predict condensation mass flux at interfaces to be used in a CFD approach related to a closed environment for space applications: planetary flights, lunar-Mars bases.

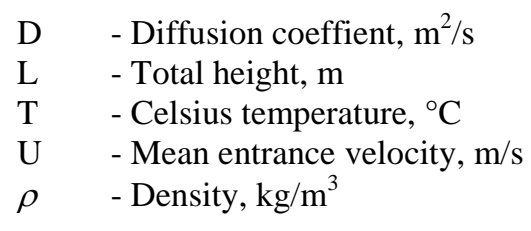

\section{Nomenclature}

${ }^{1}$ Researcher, Institut Pascal, akhilesh.tiwari77@gmail.com, non-Member.

${ }^{2}$ Professor, Institut Pascal, j-pierre.fontaine@univ-bpclermont.fr, non- Member.

${ }^{3}$ Professor Emeritus, Institut Pascal, j-bernard.gros@univ-bpclermont.fr, non- Member.

${ }^{4}$ Professor, Head of GePEB axis - Institut Pascal, c-gilles.dussap@univ-bpclermont.fr, non- Member.

${ }^{5}$ Director, UR Qualité des Produits Animaux (INRA), alain.kondjoyan@clermont.inra.fr, non- Member. 
$\mu \quad$ - Dynamic viscosity, Pa.s

$\Delta \quad$ - Difference

\section{Dimensionless parameters \\ Re - Renolds number \\ Sc - Schmidt number}

\section{Subscripts}

$\begin{array}{ll}a & \text { - ambient } \\ c & \text { - controller } \\ d & \text { - dew point } \\ f & \text { - film } \\ s & \text { - surface } \\ \text { SAT } & \text { - Saturation }\end{array}$

\section{Introduction}

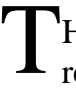
HE development of Earth like environment inside a closed-system for the progress of plant-based bioregenerative life support technologies is a challenge today. This is a requirement for long-duration exploratory manned missions to fulfil the needs of a crew including nutritional demand, atmosphere regeneration, and psychological support ${ }^{1,2}$. One of the key elements for BLSS are plants ${ }^{3-5}$, as they regenerate ambient air by photosynthesis, help water recovery by transpiration, supply fresh food or nutritional needs for crews and can be used for the recycling of wastes. A maximum of biological materials could be reused for plant cultivation after involving various effective waste processing techniques ${ }^{6-8}$.

The importance of recycling within the spacecraft, with crews consuming the products of autotrophic synthesis, needs recycling of materials, requires exchanges between photoautotrophic organisms, which synthesize organic substances using solar or artificial light, and heterotrophic organisms. Hence, growing plants is a vital component and its performance in BLSS for space missions will be principally dependent on the progress of plant cultivation technology for space and the achievement of associated equipment. The growth of higher plants in a green house is optimized by the environmental conditions among which the effect of ventilation, condensation and evaporation phenomena on the surfaces of leaves, plants, windows (reduces sun radiation), and walls. Moreover, condensation on walls or human skin has to be controlled as well as the ambient air for optimized living conditions within the spacecraft, even if the humidity level is not as high as in a greenhouse and to prevent mould, rot or rust. Furthermore, forced convection is known to be a good solution to prevent condensation while maintaining optimized conditions for life. Hence, the optimization of BLSS requires a global coupled hydrodynamics, heat and mass transfer modelling that could simulate precisely the atmosphere in spatial greenhouses, or in manned capsule. Further, the coupling with microbiological development models ${ }^{9}$ will help for the protection of the crew from nosocomial infections, the optimization of the microclimate prevailing in a space greenhouse and a better control of higher plant growth.

In BLSS, the plant culture will play an important role in food production, $\mathrm{CO}_{2} / \mathrm{O}_{2}$ conversion, and water purification. Life support for crews in space is dependent on both the amount of food and atmospheric $\mathrm{O}_{2}$ produced by plants in a limited space. In a closed chamber the enhancement of the gas exchange with leaves and growth of plants would be dependent on several factors, including control of air current. Insufficient air movement around plants generally limits their growth by reducing the gas diffusion in the leaf boundary-layer thereby decreasing photosynthetic and transpiration rates ${ }^{10-11}$. Airflow affects plant growth through energy and mass transfer, latent heat exchanged through the processes of water evaporation (transpiration) and condensation onto plant surfaces is also directly affected by air movement

Thus, the air flowing over the surface of living objects, plants or humans affects their growth and/or behaviour. Most of their activities require a thorough understanding of the local atmospheric conditions. The agricultural process depends on temperature, sunshine, absence or presence of clouds, air velocity, and on the amount of water available in the local atmosphere. The net photosynthetic rate of the plant canopy increases with increasing air velocities inside plant canopies ${ }^{12}$.

Numerical simulation or theoretical models could give insights into the dynamics of transport phenomena and assist in the design of an optimized and reliable air-conditioning system and particularly as it could help the simulation of reduced gravity conditions. However, a precise mathematical model requires the knowledge of the 
local mass transfer coefficients (for condensation or evaporation) for specific configurations, and a validated turbulent model. Such data can only be given by experimental works or by literature. The primary goal of this study was to develop an experimental setup to measure heterogeneous mass flux on a horizontal surface of small size in a well controlled air-conditioned system. The final goal was to estimate the local mass transfer coefficients on such a basic configuration.

We discuss herein the experimental setup developed at 1-g to study the coupling between the condensation mass flux and the hydrodynamics on a horizontal flat plate of in a climatic wind tunnel environment in which transport phenomena are well controlled. We have already performed a few condensation experiments in an open environment and studied, in the wind tunnel, the velocity profiles on the surface of vertical and horizontal flat plates in dry conditions ${ }^{13,14}$. This current paper presents the results obtained, in the wind tunnel, for the condensation of humid air in various conditions when the mean flow velocity varies between $1 \mathrm{~m} \cdot \mathrm{s}^{-1}$ and $3 \mathrm{~m} \cdot \mathrm{s}^{-1}$.

\section{Experimental Material and Methods}

\section{A. Global experiment}

To generate and control a flux of condensation of wet air on the surface of a flat plate, we have developed a system based on a controlled thermoelectric cooler. The temperature of the plate was kept constant in order to induce a stable flux of condensation on the active plate/air interface and the condensate mass was monitored by continuous precise weighing. The overall device was placed in a vein which hydrodynamics, temperature and humidity fields were controlled $^{15}$. The wind tunnel facility is a closed loop, sealed and highly insulated that generates runoff from nearly laminar to highly turbulent regimes. The characterization of the flow, average speed and fluctuations was performed by hot wire anemometry. Fig. 1 gives a photograph of the test chamber and the active condensation unit with water condensate on it.

\section{B. Preparation of condensation unit}

The condensation unit was prepared after extensive experiments for the definition of the geometrical and thermophysical parameters of the condensing unit: size, thickness of the plate, selection of metal substrate and heat sink, temperature distribution at the air/solid interface (ceramic surface of the Peltier element or aluminium plate above it), with the aim of generating a thermal distribution of the air/substrate interface as homogeneous as possible (it corresponds to the active side of the plate for

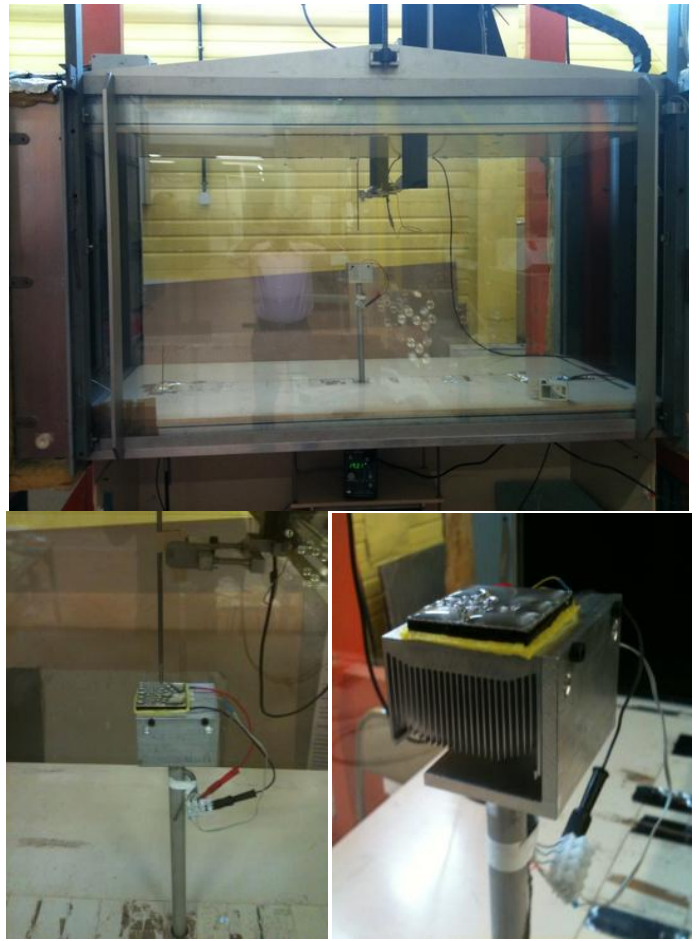

Figure 1. Photograph of the test chamber and zoom in on the condensing unit in presence of drops on top of the active surface. condensation) $^{14,16}$. 
The condensing unit consists of a square plate (2) of aluminium bonded to a thermoelectric (Peltier) module (3) of the same size $(5 \mathrm{~cm} \times 5 \mathrm{~cm})$, as seen on Fig. 2.b; the other face of the module is bonded to a heat sink (4) for the temperature of this side to be kept close to the ambient temperature $\left(T_{a}\right.$, reference temperature). The temperature of the active surface $\left(\mathrm{T}_{\mathrm{s}}\right)$ is controlled by the thermoelectric element which is regulated by means of a thermistor (1) inserted into the small plate and a controller (7) which adjusts the electric current supplied to the thermoelectric module (Fig. 2.a).

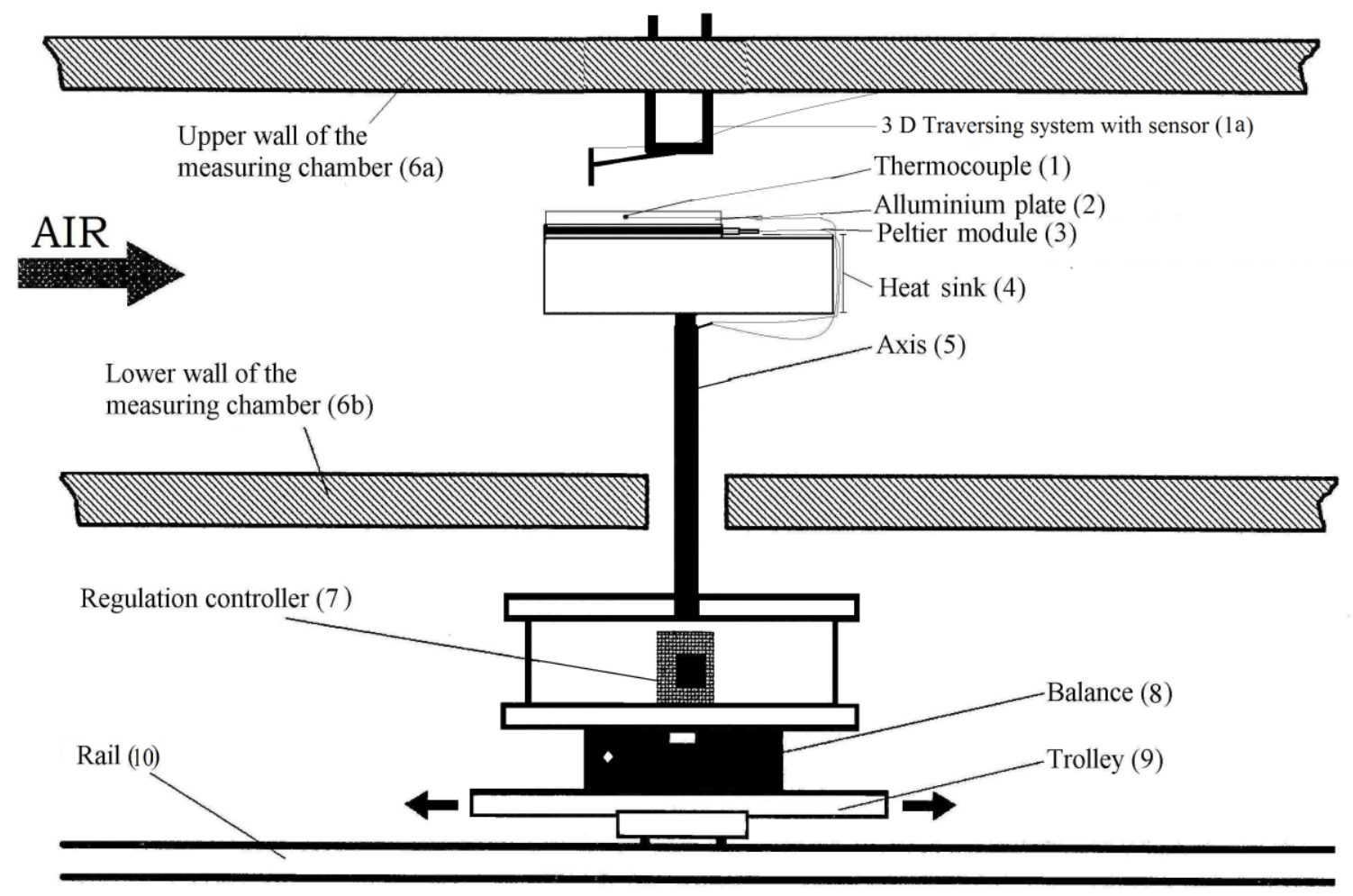

(a)

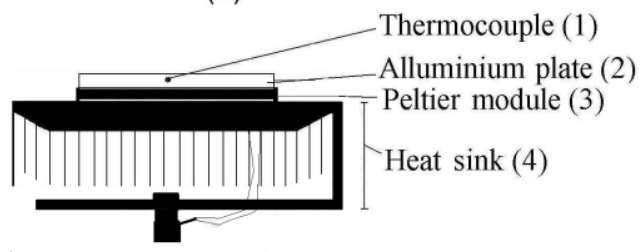

(b)

Figure 2. Sketch of the whole setup: (a) front view of the system; (b) side view of the upper part which faces the airflow.

The condensation unit is set horizontally (active horizontal plate) at the centre of the test chamber (upper part of Fig. 2). It is maintained in the measuring chamber by a shaft (5) fixed itself at the balance pan (8), located under the test chamber. Two horizontal parallel plates connected by four screws are placed on the balance; in between these two plates the temperature regulation controller (7) is placed. The wire of the Peltier module and the one of the thermistor inserted in the active plate (1) walk along the axis and are connected to the temperature controller. The balance is put on a mobile platform, a trolley (9) which makes it possible to slide the whole system on a rail (10) parallel to the direction of the flow. This device allows a continuous signal acquisition recorded by a precision balance (Mettler 30, precision of $\pm 0.1 \mathrm{~g}$ ), for monitoring the increase in weight as the humid air will condense on the active surface. A ring made of sponge is added around the upper part of the sealant of the Peltier module in order to collect the drops that are produced on the vertical side of the plate (can be seen in Fig. 7). Otherwise the drops would flow down by gravity and eventually fall on the heat sink or the lower surface of the test cell and then evaporate as these surfaces are warmer. As a result part of the produced condensate would disappear. However, such 
an absorption ring has an obvious influence on the flow that develops over the plate and thereby on the condensation conditions.

Hence, on the cold side a temperature difference $\Delta \mathrm{T}_{\mathrm{s}}=\mathrm{T}_{\mathrm{d}}-\mathrm{T}_{\mathrm{s}}$ between the active surface $\left(\mathrm{T}_{\mathrm{s}}\right)$ and the dew point $\left(\mathrm{T}_{\mathrm{d}}\right)$ can be created and induce condensation ${ }^{16}$, see Fig. 3. During the experiments the controller temperature $\left(\mathrm{T}_{\mathrm{c}}\right)$ is imposed and thus, the thermal contrast $\Delta \mathrm{T}_{\mathrm{c}}=\mathrm{T}_{\mathrm{d}}-\mathrm{T}_{\mathrm{c}}$ with the dew point, whereas $\Delta \mathrm{T}_{\mathrm{s}}$ is induced and not known precisely. Aluminium was chosen for the plate for its high thermal conductivity in order to make the active surface to be as isothermal as possible and for its corrosion properties. It is noteworthy that the size of the aluminium plate should be small enough for the active surface to be considered thermally homogeneous and large enough for the amount of condensate to be weighed accurately on the electronic balance ${ }^{14}$.

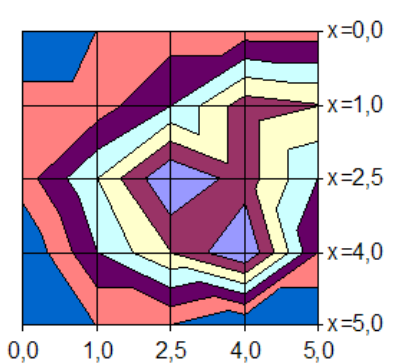

(a)

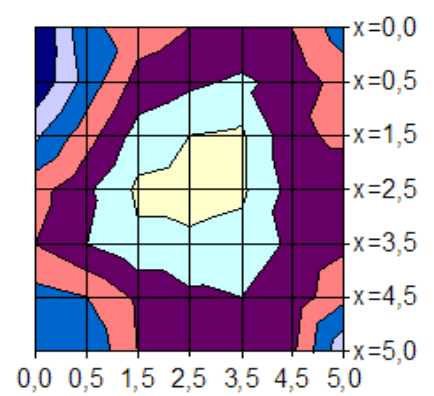

(b)

Figure 4. Temperature distribution at the solid/air interface: (a) on a $3 \mathrm{~mm}$ plate; (b) on the ceramic of the thermoelectric module.

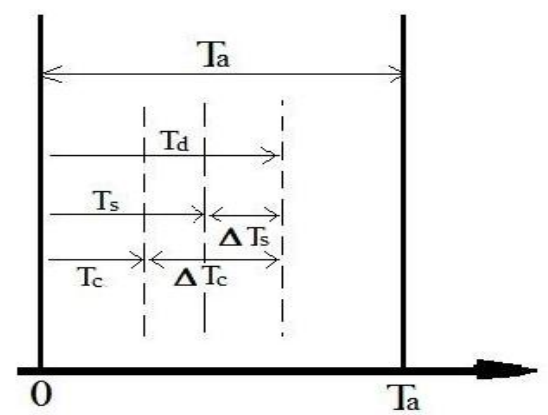

Figure 3. Different temperature levels and thermal gradients considered herein.

For the measurement procedure, the control of a steady flux of condensed vapour, with the objective of operating in a steady state regime, requires a constant temperature gradient between the dew point and the temperature of the upper surface of the plate.

The experiments conducted for the investigation of the homogeneity of the temperature profile of the upper air/substrate interface in dry conditions (above dew point) showed that the minimum variation of temperature, over the whole surface, was $0.6^{\circ} \mathrm{C}$ and the maximum was $2.4^{\circ} \mathrm{C}$ with a same size plate on the Peltier module (depending on thermal gradients imposed, flow nature, plate thickness). The maximum went up to $3.5^{\circ} \mathrm{C}$ without a plate (measured directly on the ceramic of the thermoelectric module) as in Fig. 4.b. A slightly higher temperature difference imposed in a configuration with the $3 \mathrm{~mm}$ plate depicts a $1.4^{\circ} \mathrm{C}$ surface difference only. It was experienced here that the increased mass helps in reducing the thermal in-homogeneity on the surface of the plates. Moreover, local temperature measurements of points spread all over the surface indicated similar behaviours in time when the thermal constraints varied $\left(\mathrm{T}_{\mathrm{c}}\right.$ and/or $\left.\mathrm{T}_{\mathrm{d}}\right)$. The area of the plate also plays a role; an increase helped us to produce more condensate without significantly affecting the in-homogeneity, as only minor changes were seen. It was also observed that adjusting the size of the plate to the one of the Peltier element helped in reducing the in-homogeneity of the surface of the plate.

The hot wire sensors available were calibrated at room temperature for velocity measurements, and the mean flow velocities chosen ranged between $1.0 \mathrm{~ms}^{-1}$ to $3.0 \mathrm{~ms}^{-1}$ with an accuracy of $1-3 \%$. Therefore the sample frequency of the fan for the generation of the flow inside the wind tunnel was chosen from $5 \mathrm{~Hz}$ to $40 \mathrm{~Hz}$. A three dimensional traversing system was used for the localization of the hot wire probe for data acquisition and the average velocity fluctuations was ensured using a computer connected to the system.

\section{Mass condensate measurement method}

The condensing unit including the temperature controller and all accessories were placed on the balance before condensation started. The weight of the condensing unit with all the supporting devices (such as stand, wires, heat sink, and all screws to tighten up the stand, shown in the schematic Fig. 2) was approximately $7.2 \mathrm{~kg}$, and with the addition of the temperature controller the balance indicated a weight of approximately $11.8 \mathrm{~kg}$ before the vein fan was turned on. It was proven during calibration process that the air flowing intensity had no influence on the weighing process once stability was reached. The least count of the balance was $0.1 \mathrm{~g}$ with a maximum balance limit of $30 \mathrm{~kg}$. As it is seen in Fig. 2.b the front face of the condensing unit was $7.5 \mathrm{~cm}$ wide and $6.7 \mathrm{~cm}$ high (or thickness); such sizes are very significant and strongly affect the shear zone that develops above and around the test 
plate as the flow over the plate should be more or less similar to a flow over a blunt-faced plate. In this way, the flow of air was used to cool down the fins of the heat sink and to dissipate the heat produced by the thermoelectric elements.

The controller temperature $\left(\mathrm{T}_{\mathrm{c}}\right)$ was chosen relatively to the dew point temperature. The value of $\Delta \mathrm{T}_{\mathrm{c}}=\mathrm{T}_{\mathrm{d}}-\mathrm{T}_{\mathrm{c}}$ was selected such that, a sufficient amount of condensate could be produced at the end of the experiment. In fact condensation occurs when $\Delta \mathrm{T}_{\mathrm{s}} \geq 0$, but the thermal gradient within the condensation interface and the temperature $T_{c}$ measured just below the top of the upper surface of the plate need to be counted for, even though it is not known. Once the process of condensation had started it was continued regularly till the end of the experiment without apparent interruption. The electronic balance showed an increase in weight, and this evolution was recorded in two different ways: (i) every 30 minutes, (ii) the time was recorded every $0.1 \mathrm{~g}$ mass increase (upon stability). An example of mass growth acquisition versus time according to (i) method is presented on Fig. 5; the other key environmental parameters are presented: the ambient temperature $\left(\mathrm{T}_{\mathrm{a}}-10^{\circ} \mathrm{C}\right.$ plotted), the dew point and the temperature constraint $\left(T_{c}\right)$. This experiment gives a gradient of linear square data fit of $0.42 \mathrm{~g} \cdot \mathrm{h}^{-1}$. The experimental conditions were not constant during the whole time, as one can observe from Fig. 5 that the ambient temperature was quasi-constant but the dew point increased due to an increase in the relative humidity of the daily atmosphere. The increasing tendency in the dew point only lasted $4 \mathrm{~h}$, and then became constant. This variation in a key environmental parameter affected the rate of condensation for that particular time. Similar plots were drawn for each experiment with linear least square data fits to deduce the gradient of mass with respect to time.

\section{Results and Discussions}

We focus in this paper on condensation experiments carried out in a wind tunnel of controlled psychometric parameters $\left( \pm 0.1^{\circ} \mathrm{C}\right)$ such as relative humidity, ambient temperature and dew point. The purpose was to validate the setup in a controlled environment (particularly precise weight acquisition) and finally the evaluation of the local mass transfer coefficients. Preliminary investigations in a room with no air-conditioning system, i.e. where the ambient environment changed according to the external weather conditions, have already been performed ${ }^{15}$. The goal was first to characterize each element of the design, to select the substrate (material, size, thickness, and preparation), heat sink (material, size, and suitability for use in the wind tunnel), and to calibrate the measurements of all the various sensors and second to validate that specific experimental concept for the evaluation of mass transfer coefficients.

\section{A. Amount of condensate versus time}

More than 70 condensation experiments were performed on the horizontal plate at ambient temperature. Various condensation conditions ( $\mathrm{RH}$ varied from $35 \%$ to $65 \%$ ) were simulated at room temperature (around $20^{\circ} \mathrm{C}$ ); the mean flow velocity ranged from 1 to $3 \mathrm{~ms}^{-1}$. It corresponds to Reynolds numbers between $3.10^{3}$ and $10^{4}$, where $\operatorname{Re}=\left(\rho_{\infty} U L\right) / \mu_{\infty}$ with $\mathrm{L}=5 \mathrm{~cm}$ and the Schmidt number was approximately 0.6 , where $S c=\mu_{\infty} /\left(\rho_{s} D\right)$. The experiments lasted from 3.5 to $8 \mathrm{~h}$ after condensation started. The maximum amount of condensate collected was 4.8 $\mathrm{g}$ on the plate and the minimum $0.8 \mathrm{~g}$. The temperature and hygrometry of the wind tunnel were controlled well enough, except if there was a very large variation in the exterior ambient weather conditions (humidity or temperature), a noticeable variation in internal parameters was seen accordingly. The experimental setup of the wind

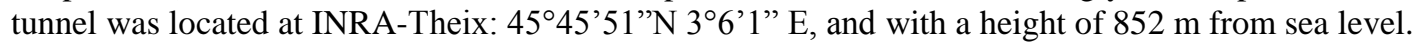


Fig. 6 shows how the amount of collected condensate is significantly affected by a variation in different environmental parameters. The plots show the amount of condensate versus time for several average temperature differences $\Delta \mathrm{T}_{\mathrm{c}}$. The trends are slightly affected by the hygrometric conditions, which are not fully stable. However, both Fig. 6.a and 6.b indicate that on increasing the temperature difference, the average rate of collection of condensate also increases accordingly. Consequently, the main trend reflects the sensitivity of the slope and, thus, of the mass flux to the temperature difference as expected. As an example, on the day of CEI-1, the dew point increased for almost $3 \mathrm{~h}$ and $\Delta \mathrm{T}_{\mathrm{c}}$ went up to $5.7^{\circ} \mathrm{C}$, then stabilized for 1 hour, and finally decreased down to $4.6{ }^{\circ} \mathrm{C}$. After more than $7 \mathrm{~h}, 2.3 \mathrm{~g}$ of condensate were collected on the plate, with an average $\Delta \mathrm{T}_{\mathrm{c}}$ value of $5.3{ }^{\circ} \mathrm{C}$, and an average fluctuation of $\pm 0.6^{\circ} \mathrm{C}$. The other plots could be detailed the same way. All condensation rates reflect roughly linear global growths with time, whose slope increases with $\Delta \mathrm{T}_{\mathrm{c}}$, as it generates the driving force through the partial pressure gradient.

From all those plots we can deduce an average speed of condensation. These values are further used to deduce the mass flux on the plate.

\section{B. Condensation patterns}

Drop wise condensation occurred every time and it was visible (very small drops in size) after a few minutes of condensation conditions. Eye observations showed that inhomogeneous distributions of drops were observed spatially and also in size. The initial growth of drops and the coalescence process were found to be as described by Beysens ${ }^{17}$, in which the bigger drops attract the smaller ones that have grown in their vicinity and thus, sweep off the metal surface around which allows for the condensation process to continue with the nucleation of tiny drops, etc. It results in the appearance of very different sized drops on the surface.

The surface of the aluminium metal flat plate was not well polished and only mechanical filing was done on the edges, and then just cleaned with ethyl alcohol by wiping out the substrate before starting each experiment. The hand filing of the substrate probably caused the drops to grow first on the edges all around the plate, as seen in Fig. 7. That experiment considered a mean velocity of $1 \mathrm{~m} \cdot \mathrm{s}^{-1}$ and it was a good representation of the various observations with very scattered drop configurations. The nature of the flow had probably a major effect on those patterns, and then on the heat-mass transfer at the surface of the plate, which shows that a perfect understanding of the global phenomena would require an accurate description of the 3D flow field above the plate, but it was not our initial purpose.
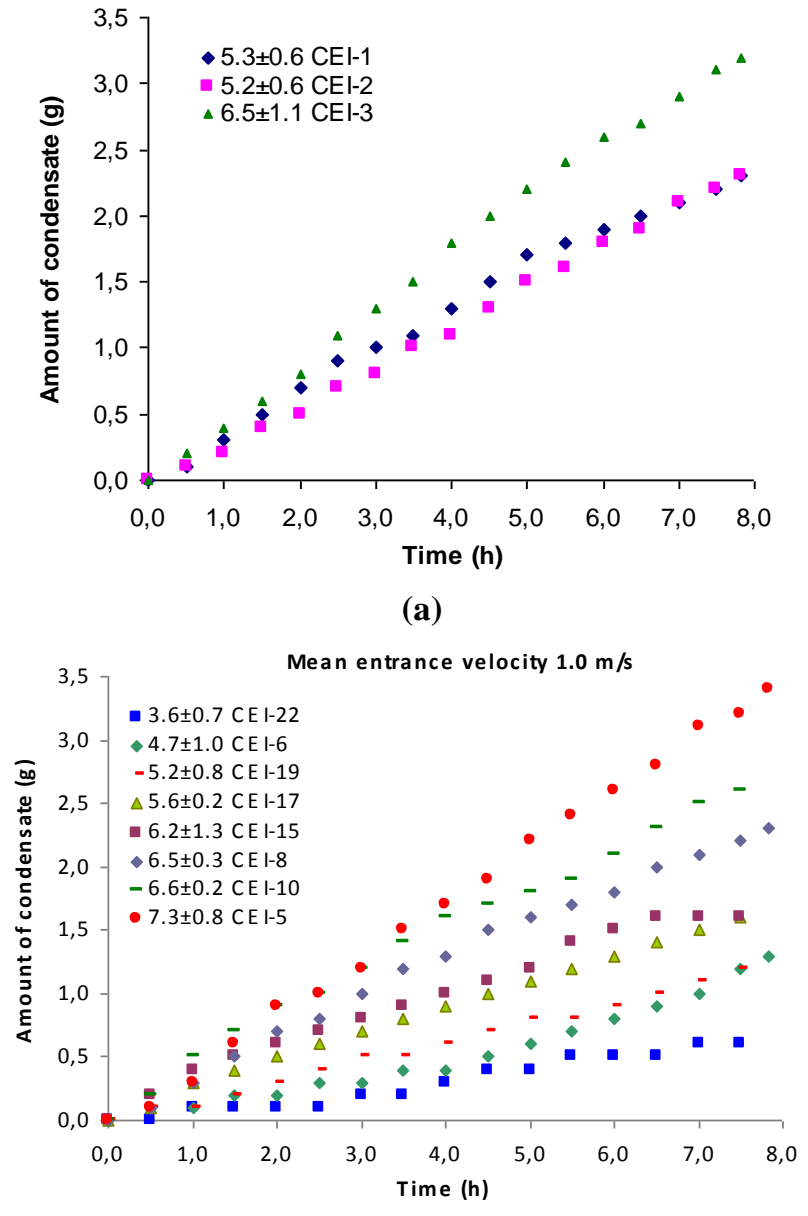

Figure 6. Amount of condensate as a function of time for different average temperature differences $\left(\Delta T_{c}\right)$, both are for the $1.0 \mathrm{~m} / \mathrm{s}$ mean entrance velocity. 
It is also worth noting that the shape of the condensate is strongly influenced by the physico-chemical properties of the aluminium plate (contact angle, etc.).

\section{Surface temperature estimation}

The calculation of the condensation mass flux involves the partial pressure gradient at the liquid/air or metal/air interface where condensation proceeds, the area of the interface and the correlated mass transfer coefficient. As usual in chemical engineering, the area is not known and the goal is to determine the $k_{L} \cdot A$ coefficient. The partial pressure of

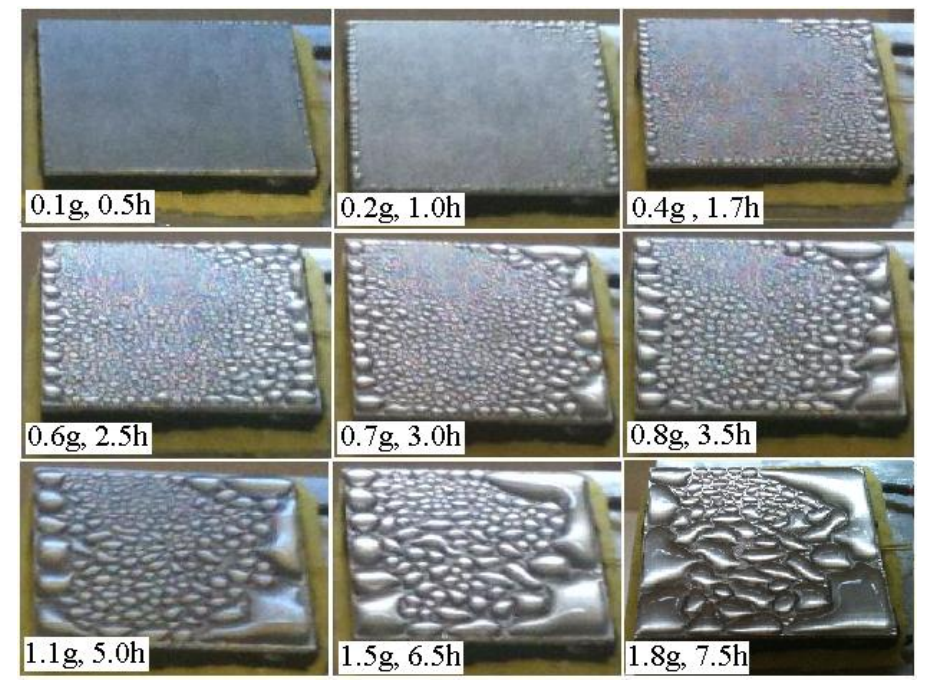

Figure 7. Photographs of the flat plate covered with condensation at different instants of an experiment. the air is deduced from the ambient temperature and the relative humidity, whereas neither the pressure nor the temperatures are known. Moreover, the only accurate data available is $T_{c}$ which is the temperature measured by contact with the thermistor inserted $1 \mathrm{~mm}$ below the metal/air surface. Modelling could have given some insights into the thermal gradient in the plate thickness and on its surface, and within the volumes (drops, masses) of condensate. But a precise CFD simulation would need to deal with a 3D transient problem that involves change of phase (mass flux again and moving interface tracking for the condensation front), and turbulent flow modelling.

Consequently, the knowledge of the surface temperature $T_{\mathrm{s}}$ of the active condensing plate became an important task for the estimation of the mass transfer coefficient relative to condensation of humid air, in addition to the mean values of the controller temperature $T_{c}$ and of the ambient temperature $T_{a}$. Moreover, the temperature set on the controller proved to be slightly smaller than just above at the interface with the air, and that there was some discrepancy in the surface temperature $\mathrm{T}_{\mathrm{s}}$ over the flat plate area (about $1{ }^{\circ} \mathrm{C}$ ) in dry air, which means that such an in-homogeneity was probably reinforced by the heterogeneous mass transfer that developed on the plate. The use of a surface sensor was not convincing because of the presence of forced convection ${ }^{16}$. This complexity encouraged us to try a few rules to estimate the surface temperature, keeping in mind that $T_{c} \leq T_{s} \leq T_{a}$. For the positive speed of condensation on the active plate, $\Delta \mathrm{T}_{\mathrm{s}}=\mathrm{T}_{\mathrm{d}}-\mathrm{T}_{\mathrm{s}}$ should be positive, we have tested:

$$
\begin{aligned}
& T_{s}=\frac{T_{c}+T_{a}}{2}=T_{c}+0.5\left(T_{a}-T_{c}\right) \\
& T_{s}=\frac{3^{*} T_{c}+T_{a}}{4}=T_{c}+0.25\left(T_{a}-T_{c}\right) \\
& T_{s}=\frac{5^{*} T_{c}+T_{a}}{6}=T_{c}+0.16\left(T_{a}-T_{c}\right)
\end{aligned}
$$

$T_{\mathrm{S}}$ calculated by equation (1), led sometimes to negative temperature differences $\left(\Delta \mathrm{T}_{\mathrm{s}}\right)$, whereas a positive rate of condensation was observed in the experiments. Eq. (2) induced a similar effect in a few experiments. That effect was not reached with eq. (3), the estimated $\mathrm{T}_{\mathrm{s}}$ resulted in positive $\Delta \mathrm{T}_{\mathrm{s}}$ for every experiment with a positive speed of condensation.

Incropera and DeWitt ${ }^{18}$ suggested, for the evaluation of all the liquid properties in the Nusselt analysis (vertical film wise condensation), to consider the film temperature as $T_{f}=\left(T_{s a t}+T_{s}\right) / 2$, where $T_{\text {sat }}$ is the saturation temperature and $T_{s}$ is the surface temperature. On using this rule with $T_{s a t}=T_{d}$ and $T_{s}=T_{c}$, we have calculated the surface temperature as $T_{s}=\left(T_{d}+T_{c}\right) / 2$, and found that this value is approximately $\left( \pm 1.0{ }^{\circ} \mathrm{C}\right)$ equal to the one calculated with eq. (3).

In heat transfer problems and for the evaluation of the Nusselt number in vertical configurations, Minkowycz and Sparrow ${ }^{19}$ proposed the use of a reference temperature defined by $T_{r e f}=T_{c}+0.31\left(T_{a}-T_{c}\right)$. The authors also reported that for the estimation of heat transfer coefficient the Nusselt model gave a good agreement with their results taking into account variable physical properties evaluated with that reference temperature.

We have also considered two "limit" cases to calculate $\mathrm{T}_{\mathrm{s}}$ 


$$
\begin{aligned}
& T_{s}=T_{c}+1.0 \\
& T_{s}=T_{d}
\end{aligned}
$$

Indeed, eq. (4) gives an approximate of the minimum possible surface temperature according to our surface temperature investigation in dry air, and eq. (5) gives a maximum possible temperature for condensation to start, as the condensation can only occur when $\mathrm{T}_{\mathrm{s}}<\mathrm{T}_{\mathrm{d}}$.

\section{Mass flux evaluation for a mean flow velocity of $1 \mathrm{~m} . \mathrm{s}^{-1}$}

Finally we used eq. (3) to estimate the surface temperature $T_{s}$, and thus, we could deduce the mass flux on the plate by considering the area of the plate $(5 \mathrm{~cm} \times 5 \mathrm{~cm})$ as the mass transfer exchange surface.

The dependence of the mass flux as a function of the average temperature difference $\Delta T_{\mathrm{s}}$ is depicted on Fig. 8.a, and as a function of the mean difference in partial pressure $\left(\Delta \mathrm{p}=\mathrm{p}_{\mathrm{sat}}-\mathrm{p}_{\mathrm{s}}\right.$, between the saturated vapour partial pressure of the man flow and the partial pressure at $\mathrm{T}_{\mathrm{s}}$ ) in Fig. 8.b. Each experimental point corresponds to a 6-8 $\mathrm{h}$ experiment. The experimental value results from the algebraic average over the whole experiment duration of the data points evaluated at each time of measurement; the "slope" corresponds to the gradient of the curves plotted for the increase in weight with time for each experiment ${ }^{15}$ (see section II.C and Fig. 5). The improperly called "theory" data correspond to the arithmetic mean of points calculated using the environmental data recorded at the time of the experiment and by assuming a heat/mass analogy for the mass flux evaluation of a simple 1D stationary model: the heat flux is the one that would be calculated for a flat horizontal plate covered by a film of condensate when a laminar boundary layer flow develops on top ${ }^{16}$. The theoretical data show the best fits, particularly in Fig. 8.b $(\Delta p)$. The data are more scattered in Fig. 8.a $\left(\Delta \mathrm{T}_{\mathrm{s}}\right)$, particularly for the calculated ones, which seems to indicate that the difference in partial pressure is a better indicator than the difference in temperature for the estimation of the mass flux for the current configurations. Indeed the driving force for condensation mass transfer (controlled by the diffusion of water vapour towards the condensation interface) is better modelled by partial pressure differences than temperature differences solely (no interaction with the relative humidity which is a key factor, as minor deviation in $\mathrm{RH}$ level (5\% is enough) during an experiment influence significantly the condensation rate; such an effect cannot be counted for when only $\Delta \mathrm{T}_{\mathrm{s}}$ are considered. As a matter of fact, a long variation in RH would act as a spurious mode, as the global problem is multi-parametric and the bi-dimensional plots given herein can only deal with 1 to 3 parameters only.

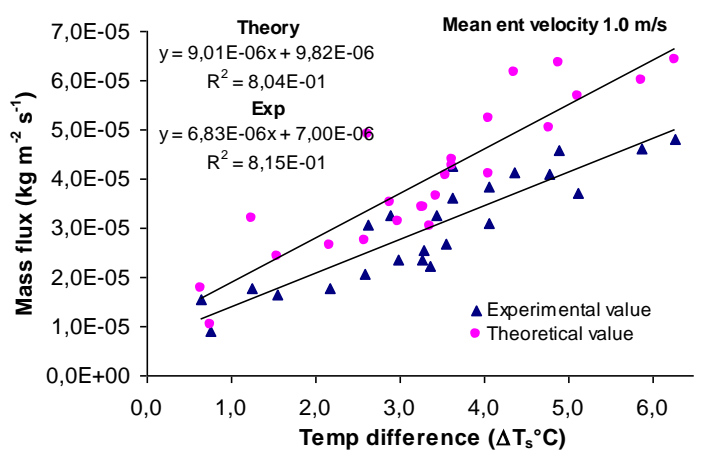

(a)

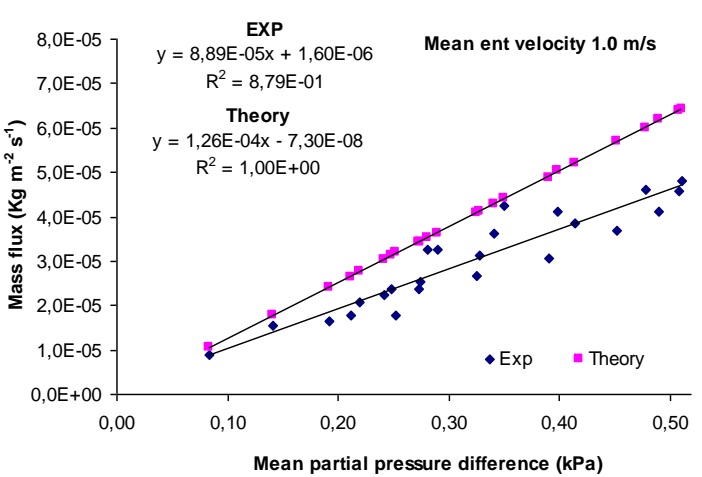

(b)

Figure 8. Mass flux for a mean entrance velocity of $1.0 \mathrm{~m} / \mathrm{s}$ as a function of: a) the temperature difference $\left(\Delta T_{\mathrm{s}}\right)$, (b) the mean partial pressure difference.

For the experimental data, variations in the experimental conditions can justify most of the scattering in data. The global experimental setup did not allow us to be more precise and to conduct experiments at a specific ambient temperature coupled with a specific relative humidity over 7 hours as, even sealed and insulated, the air in the closed loop was slightly affected by outside environmental conditions after a few hours.

\section{E. Influence of the mean entrance velocity}

An increase in the air flow intensity to $1.5 \mathrm{~m} . \mathrm{s}^{-1}$ and further to $2.5 \mathrm{~m} . \mathrm{s}^{-1}$ is described in Fig. 9. The mass flux variations show trends more or less similar between the experimental data and the modelled ones. In both cases, but 
it is noticeable with fewer data, the scattering is much reduced for partial pressure difference and temperature difference as well.

The theoretical data in Fig. 9.b reflect 100\% linearity in the mass flux versus the partial pressure difference plot shows, and $95-96 \%$ for the experimental ones. The gradient of mass flux with partial pressure difference keeps increasing and amounts to $1.29 \times 10^{-4}$ in the experiments and $1.52 \times 10^{-4}$ for the model (18\% more) at $1.5 \mathrm{~m} . \mathrm{s}^{-1}$. That increase gets higher for $2.5 \mathrm{~m} . \mathrm{s}^{-1}$, as it reaches $1.46 \times 10^{-4}$ and $1.98 \times 10^{-4}$ with the model (almost $36 \%$ more). When increasing the flow intensity further, similar results were found; the gradient of mass flux with temperature difference is always lower than with partial pressure difference, also the theoretical values are always higher than the experimental ones.

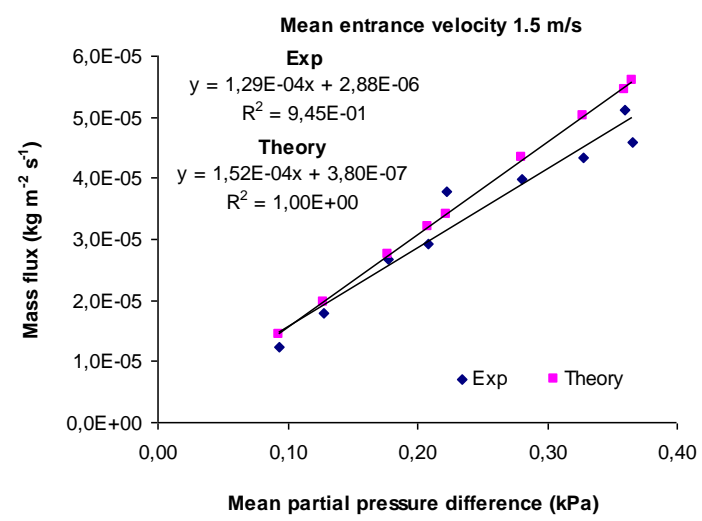

(a)

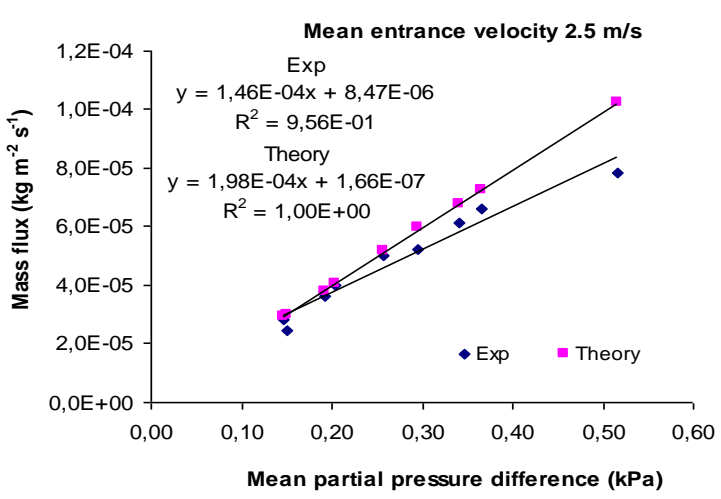

(b)

Figure 9. Mass flux as function of mean partial pressure difference (kPa) for a mean entrance velocity of (a) $1.5 \mathrm{~m} / \mathrm{s}$ and (b) $2.5 \mathrm{~m} / \mathrm{s}$.

In addition, we found that, for the studied 1-3 $\mathrm{m}_{\mathrm{s}} \mathrm{s}^{-1}$ velocity range, the regression coefficients of the mass flux with partial pressure difference reached nearly $100 \%$ fit for the model, and slightly less for the experiments. In opposition, the regression coefficients for the temperature difference plots were most of the time higher for the experimental data than for the theoretical ones. For $1.0 \mathrm{~m} / \mathrm{s}$ (Fig. 8) many more data were available, but these data covered more variations in physical environmental conditions: $\left(\Delta \mathrm{T}_{\mathrm{c}}\right)$ was in the range $3.4^{\circ} \mathrm{C}-9.8{ }^{\circ} \mathrm{C}$, while the relative humidity was in $43-63 \%$ for a total of 24 data points. For $1.5 \mathrm{~m} / \mathrm{s}, \Delta \mathrm{T}_{\mathrm{c}}$ was in $3.3{ }^{\circ} \mathrm{C}-8.2{ }^{\circ} \mathrm{C}$ and $\mathrm{RH}$ in 38 $48 \%$, with a total of 9 data points only.

On increasing the mean entrance velocity inside the wind tunnel, the mass flux has a tendency to increase but not according to a linear variation. The histogram shown in Fig. 10.a corresponds to the variation of the mass flux $\left(\mathrm{N}_{\mathrm{A}}\right)$ with respect to the mean partial pressure difference as a function of the mean entrance velocity for the experimental data and in Fig. 10b for the calculated data. On those plots one can read the mass transfer coefficients we investigated for condensation over a horizontal plate. The imposed temperature difference, $\Delta \mathrm{T}_{\mathfrak{c}}$, in the experiments were chosen in the range $1.2{ }^{\circ} \mathrm{C}$ to $4.1{ }^{\circ} \mathrm{C}$, which was quite low in comparison to the regulated environment of the wind tunnel. Fig. 10.a (experimental data) shows a mass flux coefficient for $2.0 \mathrm{~m} / \mathrm{s}$ with a higher value in comparison to the other entrance velocities. It was caused by the higher temperature differences chosen during these specific condensation experiments and dome of their duration, the physical environmental parameters have recorded large variations for this selected velocity. Fig. 10 establish clearly the raise in the mass transfer coefficients on increasing the velocity inside the wind tunnel, that result was expected as on raising the mean entrance velocity the condensation surface faces stronger convective flows and thus, the diffusion layer that develops above the condensation interface should be getting thinner and ease the diffusion of water vapour molecules. Nevertheless, during these measurements the range of the average physical parameters was not the same. 


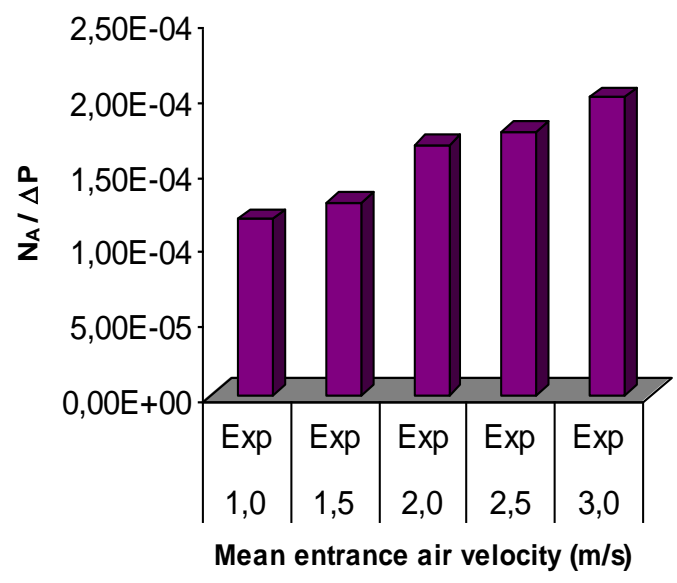

(a)

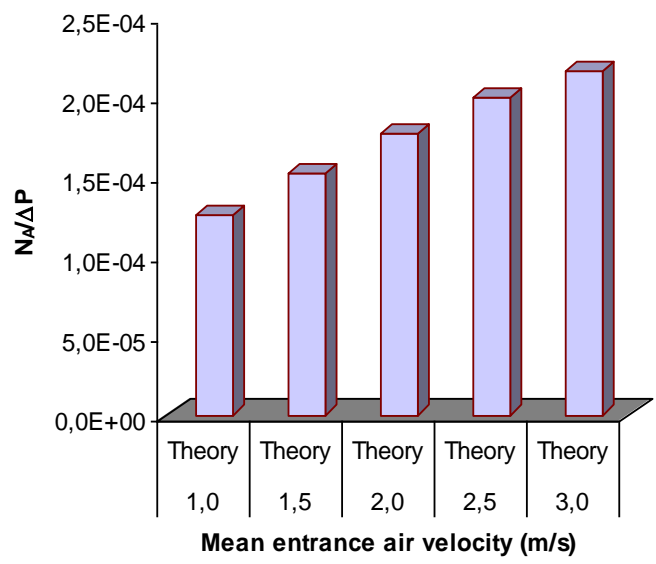

(b)

Figure 10. Plots of $N_{A} / \Delta p$ as a function of the mean entrance velocity for (a) the experimental data, and (b) the theoretical data. Scattered experimental data were removed to reduce the discrepancy.

\section{Conclusion}

The modeling of a closed ecological life support system for space flights or space bases requires apprehending precisely the air flow conditions (quality, hydrodynamics, heat transfer, humidity transfer, $\mathrm{CO}_{2}$ concentration, $\mathrm{O}_{2}$ concentration, etc.) for the optimization of the system and for the improvement of the living conditions, of maintenance and particularly of the gas/liquid transfer exchanges at interfaces. Such a complex modeling is based on local mass transfer coefficients. We have developed an experimental setup and protocol to measure such coefficients for specific geometries in a well controlled environment (climatic wind tunnel) on Earth. The use of thermoelectricity to produce a homogeneous surface temperature coupled with a precise weighing for the condensation of humid air on a small size substrate proved to be efficient for the evaluation of local mass transfer coefficients. This study focused on the characterization of condensation on a flat horizontal plate of small size in a low $R e$ number turbulent flow, which corresponds to configurations that can be encountered in a spatial greenhouse or a manned capsule. The variation of the mean flow velocity inside the wind tunnel showed an expected significant effect on the mass transfer coefficients. Further investigation will try to better understand the flow regime and the coupling with the obtained condensation patterns in order to deepen the characterization of the particular condensation phenomenon.

\section{Acknowledgments}

The authors are thankful to the Centre National d'Etudes Spatiales (CNES), France for providing financial support.

\section{References}

${ }^{1}$ De Micco, V., Buonomo, R. et al., "Soybean cultivar selection for Bioregenerative Life Support Systems (BLSS) Theoretical selection" Advances in Space Research, 2012, DOI:10.1016/j.asr.2012.02.022.

${ }^{2}$ Zimmerman, R., "Growing pains", Air and Space, August-September, 31- 35, 2003.

${ }^{3}$ Perchonok, M., Bourland, C. "NASA food systems: past, present, and future", Nutrition 18, 2002, pp.913-920.

${ }^{4}$ Salisbury, F.B., Gitelson, J.I., Lisovsky, G.M. "Bios-3: Siberian experiments in bioregenerative life support”, Bioscience 47, 1997, pp.575-585.

${ }^{5}$ Wolverton, B.C., "Higher Plants for Recycling Human Waste into Food, Potable Water and Revitalized Air in a Closed Life Support System", Earth Resources Laboratory, National Aeronautics and Space Administration, NASA-TM-87550, 1980.

${ }^{6}$ Wignarajah, K., Pisharody, S., Fisher, J.W. "Can incineration technology convert CELSS wastes to resources for crop production? A working hypothesis and some preliminary findings", Adv. Space Res. 26, 2000, pp.327-333.

${ }^{7}$ Zolotukhin, I.G., Tikhomirov, A.A., Kudenko, Y.A., et al. "Biological and physicochemical methods for utilization of plant wastes and human exometabolites for increasing internal cycling and closure of life support systems" Adv. Space Res. 35, 2005, pp.1559-1562. 
${ }^{8}$ Gros, J.B., Poughon, L., Lasseur, C., et al. "Recycling efficiencies of C,H,O,N,S, and P elements in a biological life support system based on micro-organisms and higher plants", Adv. Space Res. 31, 2003, pp.195-199.

${ }^{9}$ Mergeay M, Verstraete W, Dubertret G, Lefort-Tran M, Chipaux C, Binot R., 1988, "MELISSA - a microorganisms based model for CELSS development" Proceedings of the 3rd symposium on space thermal control \& life support system, Noordwijk, The Netherlands, October 3-6, 1988.

${ }^{10}$ Yabuki K and Miyagawa H, 1970, Studies on the effect of wind speed on photosynthesis. Jpn. J. Agric. Met.,26, 137-142 (in Japanese with English summary).

${ }^{11}$ Monteith JL and Unsworth MH, 1990, In: Principles of Environmental Physics, Edward and Arnold Publishing Co, London, p. 291.

${ }^{12}$ Kitaya Y, Shibuya T, Yoshida, Kiyota M, 2004, Effects of air velocity on photosynthesis of plant canopies under elevated $\mathrm{CO}_{2}$ levels in a plant culture system, Advances in space research, 34, issue 7, 1466-1469.

${ }^{13}$ Tiwari, Akhilesh, and Fontaine, Jean-Pierre "Towards the prediction of heat \& mass transfer in an air-conditioned environment for a life support system in space”, Water, Air, \& Soil Pollution: Focus, Vol. 9, No. 5-6, Dec. 2009 , pp.539-547.

${ }^{14}$ Tiwari, Akhilesh, Lafon, Pascal, Kondjoyan, Alain, and Fontaine, Jean-Pierre "Experimental modelling for the prediction of heat and mass transfer in an air-conditioned space environment for life support systems", Proceedings of the 40 ${ }^{\text {th }}$ ICES -2010, Barcelona, Spain, AIAA2010-6171, 2010.

${ }^{15}$ A. Tiwari, P Lafon, A Kondjoyan and JP Fontaine, 2011, An air-conditioned wind tunnel environment for the study of mass and heat flux due to condensation of humid air, Chapter 4, In: Wind Tunnels: Aerodynamics, Models and Experiments, Editor- JD Pereira, Nova Science Publishers, Inc., New York, USA, 2011 (ISBN 978-1-61209-1).

${ }^{16}$ Tiwari, Akhilesh, 2011, "Characterisation of mass transfer by condensation of humid air on a horizontal plate", PhD Thesis, Blaise Pascal University, Clermont-Ferrand, France.

${ }^{17}$ Beysens, D., "Dew nucleation and growth", C. R. Physique, 7, 2006, pp.1082-1100.

${ }^{18}$ Incropera, F.P., DeWitt DP, 1990, Fundamentals of Heat and Mass Transfer, 3rd ed. John Wiley \& Sons, Inc., New York.

${ }^{19}$ Minkowycz, W.J., Sparrow EM, "Condensation heat transfer in the presence of noncondensables, interfacial resistance, variable properties and diffusion”, Int. J Heat Mass Transfer, 9, 1966, pp.1125-1144.

${ }^{20}$ Asano, K., 2006, Mass Transfer-From fundamentals to modern industrial applications, Wiley-VCH, Weinheim, Grmany. 